\title{
The accuracy of multidetector Computed Tomography for preoperative staging of renal cell carcinoma
}

\author{
Yinghua Liu, Turun Song, Zixing Huang, Suchuan Zhang, Yuan Li \\ Department of Pediatric Surgery (YL, YL), Department of Urology (TS), Department of Radiology (ZH) \\ and Lab department of Zigong First Hospital (SZ), West China Hospital, Sichuan University, China
}

\begin{abstract}
Purpose: The purpose of this study was to evaluate the accuracy of multidetector computed tomography (MDCT) in the preoperative staging of renal cell carcinoma (RCC). Materials and Methods: We retrospectively reviewed the clinical and pathological records of 312 patients with RCC who underwent staging MDCT before surgery. Radiographic findings were compared to the findings at surgery and pathological examination. All staging used 2009 updated TNM classification.

Results: The difference in tumor size between radiographic and pathological findings was $0.21 \mathrm{~cm}$. In T1a group, the difference was $0.33 \mathrm{~cm}$. Agreement between MDCT and histopathological findings was moderate for T staging (Kappa $=0.469)$, fair for $\mathrm{N}$ staging (Kappa = 0.322), and excellent for M staging (Kappa = 0.932). The sensitivity and specificity of MDCT in detecting perinephric fat invasion were 32.26\% and 85.87\%, in detecting tumor thrombosis were $84 \%$ and $100 \%$, in detecting adrenal gland invasion were $60 \%$ and 95.79\%, in detecting lymph node involvement were 50\% and 96.36\%, in detecting distant metastasis were 100\% and 99.67\%, respectively. In regard to stage grouping, 237 of 314 patients were correctly staged by MDCT, with an overall accuracy of $75.48 \%$.

Conclusions: MDCT with a dynamic contrast protocol is able to delineate RCC with high accuracy. However, a great portion of tumors were overstaged by MDCT because of overestimation of tumor size and poor visualization of infiltration of the perinephric fat. In addition, nodal metastatic lesion evaluation relies on node size only and remains a difficult task.
\end{abstract}

ARTICLE INFO

Key words:

Carcinoma, Renal Cell;

Multidetector Computed

Tomography; Surgery

Int Braz J Urol. 2012; 38: 627-36

Submitted for publication:

March 08, 2012

Accepted after revision:

July 27, 2012

\section{INTRODUCTION}

Renal cell carcinoma (RCC) is the most common primary renal malignant neoplasm in adults. It accounts for approximately 90\% of renal tumors and 3.8\% of all adult malignancies. 1 Approximately 58,240 new cases of RCC and 13,040 deaths are expected to have occurred in the United States in 2010 (1). With the increasing use of cross-sectional imaging modalities, incidence of serendipitously discovered RCC has risen dramatically (2). Of the incidentally discovered tumors, a prominent proportion were considered small $(<4 \mathrm{~cm})(2)$.

Although radical nephrectomy remains the standard treatment for both localized and advanced RCC in patients with a normal contralateral kidney, surgical techniques have evolved over the years. Currently, nephron sparing surgery (NSS) has been proposed in the treatment of patients with localized small tumor (3). Therefore, detailed preoperative information regarding 
tumor location, size, organ confinement, presence and extent of tumor thrombus in vena cava, lymph node involvement and visceral metastasis are important for planning of surgical approach and providing accurate prognostic information for patient.

Staging of RCC is the most important factor affecting the prognosis and survival of patients. Currently, the most applied staging system for RCC is TNM classification including the most prominent histopathological features, such as tumor size, tumor extension and tumor thrombus. In preoperative staging of the RCC, imaging modalities are expected to adequately evaluate these parameters. Although a variety of examinations (ultrasound [US], magnetic resonance imaging [MRI], angiography) can be used in the workup of patients with suspected RCC, the preferred method of imaging these patients is dedicated renal computed tomography (CT) (4). Since the introduction of multidetector computed tomography (MDCT) in late 1990s, it has won popularity in preoperative imaging of RCC for its high spatial resolution, high speed of acquisition and imaging reformatting in any plans which can provide excellent anatomical details $(5,6)$.

The aim of the present study was to evaluate the accuracy of MDCT in preoperative staging of RCC, by taking the postoperative histopathological staging as the reference method.

\section{MATERIALS AND METHODS}

We retrospectively reviewed the clinical and pathological records of patients with RCC who underwent radical nephrectomy or NSS between January 2008 and June 2010. All patients who had triphasic enhanced MDCT scan done at our institution within two weeks prior to surgery were included. Patient with cystic lesion, preoperative arterial embolization, positive surgical margins or known hereditary disease such as Von Hippel-Lindau and tuberous sclerosis were excluded. Papillary RCC was defined as a tumor with largest diameter larger than $5 \mathrm{~mm}$ and those of less than $5 \mathrm{~mm}$ considered papillary adenoma were excluded. In patients with multiple unilateral tumors, the largest tumor was included.
When tumors were found in bilateral kidneys, both were taken into consideration. Both radiographic and histopathologic staging used 2009 updated TNM classification.

\section{MDCT imaging}

All MDCT scans were performed using a 64-slice MDCT scanner (Philips Brilliance, Germany) with a 0.5 second gantry rotation speed, a tube voltage of $120 \mathrm{KV}$, and a tube current of $250 \mathrm{mAs}$. In all patients, four phases image were obtained: an unenhanced scan from the thorax to the kidney to identify possible lung metastasis, renal calcification and intratumoural fat; a arterial phase from diaphragm to lower pole to evaluate the renal cortex, renal arteries, and tumor vascularization; a parenchymal phase from diaphragm to lower pole to detect small lesions and assess renal venous drainage; and a excretory delayed phase from lower pole to bladder to evaluate the relationship between the tumor and collecting system.

When performing unenhanced CT scan, a collimation of $5 \mathrm{~mm}$, thickness of $5 \mathrm{~mm}$, a table speed of $5 \mathrm{~mm}$ per revolution, and an image reconstruction interval of $5 \mathrm{~mm}$ were used. Contrast enhanced scanning was performed using collimation of $5 \mathrm{~mm}$, thickness of $2 \mathrm{~mm}$, reconstruction interval of $1 \mathrm{~mm}$, and a table speed of 5 $\mathrm{mm}$. For each study, $120-200 \mathrm{~mL}(2 \mathrm{~mL} / \mathrm{kg})$ of iodinated contrast agent (Iopromide, Ultravist 320 $\mathrm{mgl} / \mathrm{mL}$, Bayer Schering Pharma AG, Guangzhou, China) was injected intravenously at $3 \mathrm{~mL} / \mathrm{sec}$ through an antecubital vein. Arterial-phase and parenchymal venous phase images were obtained after a 30-second delay and a 60-second delay, respectively. The excretory phase was acquired 5 minutes after the beginning of the injection.

\section{Image evaluation}

CT scan examinations were re-reviewed in a purposeful manner, by a single experienced radiologist who was unaware of the histopathological results. Tumor staging included the following parameters: tumor location; tumor diameter (the largest of craniocaudal, anterioposterior, and transverse planes was defined as the radiological size), invasion of perinephric fat (determined 
by the presence of small hyperdense strands and nodules surrounding the lesion); involvement of the adrenal gland or satellite lesions within the Gerota's fascia; presence and extent of tumor thrombus, lymph node involvement and visceral metastasis. Renal hilar, paraaortic, and paracaval lymph nodes with short-axis diameter $>1 \mathrm{~cm}$ were considered to be positive.

\section{Surgical Results}

All histopathological specimens were reviewed by urological pathologists and histological subtype was classified following the 2004 WHO classification of RCCs. All tumors were graded according to the 1982 Fuhrman grading system. Pathological size was defined as the maximal transaxial diameter on specimen.

\section{Statistical Analysis}

All radiographic findings were compared with operative and pathological findings. Tumor size was analyzed as a continuously variable and analyzed by either the two-tailed Student t test or one-way analysis of variance, when appropriate. Agreement between the two staging systems was determined using the kappa statistic (0.000.20, poor; 0.20-0.40, fair; 0.40-0.60, moderate; 0.60-0.80, good; and 0.80-1.00, excellent). Statistical analysis was performed using SPSS software package version 16.0 (Statistical Package for Social ScienceTM, Chicago, IL, USA) and $p<$ 0.05 was considered to be statistical significant.

\section{RESULTS}

\section{Surgical findings}

312 patients with histopathologically confirmed 314 RCC were included: in two men, bilateral tumors were found. The mean age of all included patients was $54.99 \pm 1.41$ years old (range, 10-83 year). Patients with both bilateral tumors and another 91 patients underwent NSS and 219 patients were submitted to unilateral radical nephrectomy. Histological characteristic was evaluated in all RCC, revealing the following results: clear cell $(n=285)$, papillary cell ( $n$
$=12)$, chromophobe $(n=10)$, unclassified $(n=3)$, multiple cystic $(\mathrm{n}=3)$, XP11.2 translocation ( $=1)$. Fuhrman grade I $(n=11)$, grade II $(n=154)$, grade III $(n=121)$, grade IV $(n=27)$. The mean pathological tumor size was $4.92 \pm 2.58 \mathrm{~cm}$. The mean size of T1a tumors $(\mathrm{n}=158)$ was $3.14 \pm$ $0.77 \mathrm{~cm}$, of T1b tumors $(\mathrm{n}=87) 5.47 \pm 0.68 \mathrm{~cm}$, of T2a tumors $(\mathrm{n}=20) 8.47 \pm 0.95 \mathrm{~cm}$, of T2b tumors $(\mathrm{n}=8) 11.38 \pm 1.09 \mathrm{~cm}$, of T3a tumors (n = 30) $7.56 \pm 3.92 \mathrm{~cm}$, of T3b tumors $(\mathrm{n}=4) 7.75$ $\pm 2.84 \mathrm{~cm}$, of T3c tumors $(\mathrm{n}=2) 7.75 \pm 1.06 \mathrm{~cm}$, of T4 tumors $(\mathrm{n}=5) 8.20 \pm 3.09 \mathrm{~cm}$. There were 31 tumors with perinephric fat invasion (9.87\%), 25 tumors with renal vein or vena cava thrombosis (7.96\%), 5 tumors with adrenal involvement (1.59\%). 12 tumors were detected with lymph node invasion (3.82\%) (4 N1, 8 N2). Metastatic lesions were found in 7 tumors with three in lung, two in vertebrae or ribs and two in liver.

\section{MDCT findings}

The mean radiographic size of all included tumors was $5.13 \pm 2.52 \mathrm{~cm}, 0.21 \mathrm{~cm}$ larger than the mean pathological size $(\mathrm{P}=0.001)$. Primary T1 and T2 RCC are defined as tumors limited to the kidney. As pointed out by Catalano (7), presence of a well-defined pseudocapsule is an important finding to predict confined renal tumor (Figure-1). In the T1a group, the increment of tumor size was $0.33 \mathrm{~cm}(\mathrm{P}<0.001) .124$ of 314 tumors were staged as T1a (34.59\%), 75 tumors as T1b (23.89\%), 24 tumors as T2a (7.64\%), 3 tumors as T2b (0.96\%), 69 tumors as T3a (21.97\%), 1 tumors as T3b (0.32\%), 1 tumor as T3c $(0.32 \%)$, 17 tumors as T4 (5.41\%). With respect to primary T staging, 196 tumors were correctly staged by MDCT and the overall accuracy was $62.42 \%$ (Table-1). In T1a tumors, 45/158 were overstaged; in T1b tumors, 34/87 were overstaged, 10/87 were understaged; in T2a tumors, 7/20 were overstaged, 2/20 were understaged; in T2b tumors, $4 / 8$ were overstaged, $2 / 8$ were understaged; in T3a tumors, 4/30 were overstaged, 5/30 were understaged; in T3b tumors, 3/4 were overstaged; in T3c tumors, $1 / 2$ were understaged; in T4 tumors, $1 / 5$ were understaged.

Evidence of perinephric fat invasion was presented in 50 tumors on image evaluation 
Table 1 - Histopathological information of all included tumors.

\begin{tabular}{|c|c|c|}
\hline & No. tumors & Tumor size(cm) \\
\hline Included tumors & 314 & $4.92 \pm 2.58$ \\
\hline \multicolumn{3}{|c|}{ Histopathological subgroup } \\
\hline Clear cell & 285 & \\
\hline Papillary cell & 12 & \\
\hline Chromophobe & 10 & \\
\hline Unclassified & 3 & \\
\hline Multiple cystic & 3 & \\
\hline XP11.2 translocation & 1 & \\
\hline \multicolumn{3}{|l|}{ Fuhrman grade } \\
\hline I & 11 & \\
\hline$\|$ & 154 & \\
\hline III & 121 & \\
\hline IV & 27 & \\
\hline \multicolumn{3}{|l|}{ Primary T stage } \\
\hline T1a & 158 & $3.14 \pm 0.77$ \\
\hline$T 1 b$ & 87 & $5.47 \pm 0.68$ \\
\hline $\mathrm{T} 2 \mathrm{a}$ & 20 & $8.47 \pm 0.95$ \\
\hline $\mathrm{T} 2 \mathrm{~b}$ & 8 & $11.38 \pm 1.09$ \\
\hline ТЗа & 30 & $7.56 \pm 3.92$ \\
\hline T3b & 4 & $7.75 \pm 2.84$ \\
\hline T3c & 2 & $7.75 \pm 1.06$ \\
\hline T4 & 5 & $8.20 \pm 3.09$ \\
\hline
\end{tabular}

(Figure-2) (Table-2); only 10 were confirmed by specimen examination. In the patients with tumor thrombosis, MDCT was able to correctly identify and localize the presence and level of the thrombus in 21 patients. Of which, 13 were of thrombosis in renal vein (Figure-3), 7 in inferior vena cava (Figure-4) and 1 in inferior vena cava and pulmonary vein. Though focal enhancement of venous wall or infiltration of adjacent soft tissue is suggestive of venous wall infiltration, especially in vena cava, MDCT failed to detect another 4 tumors with venous wall invasion ( 2 in renal vein, 2 in inferior vena cava). Direct invasion of ipsilateral adrenal gland was suspected in 16 patients on MDCT (Table-2) and only 3 had tumor involvement on specimen. Another two patients with ipsilateral adrenal gland invasion were not detected on imaging evaluation.

In the evaluation of lymph node involvement which included renal hilar, paraaortic, or paracaval lymph nodes, 297 tumors were staged

Figure 1 - Confined renal tumor with a well-defined pseudocapsule (arrow).

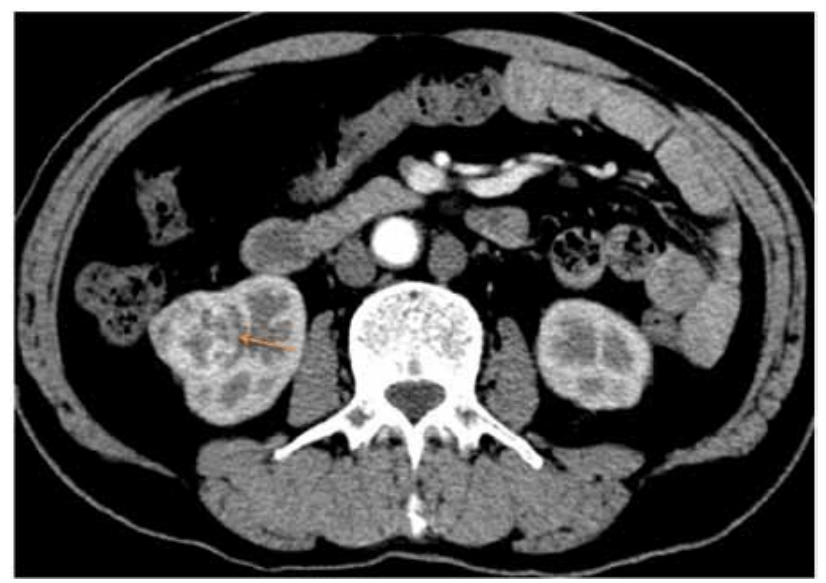

Figure 2 - Renal tumor with prinephric fat invasion, the presence of small hyperdense strands and nodules surrounding the lesion (arrow).

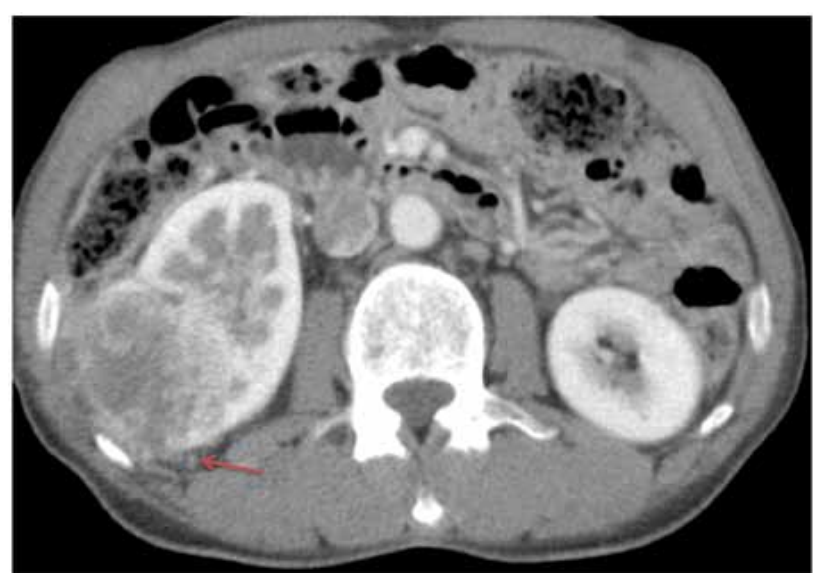


Table 2 - Histopathology and multidetector computed tomography (MDCT) staging of tumors (T).

\begin{tabular}{|c|c|c|c|c|c|c|c|c|c|c|}
\hline & & \multicolumn{8}{|c|}{ MDCT } & \multirow[t]{2}{*}{ Total } \\
\hline & & T1a & $\mathrm{T} 1 \mathrm{~b}$ & $\mathrm{~T} 2 \mathrm{a}$ & $\mathrm{T} 2 \mathrm{~b}$ & Т3a & T3b & $\mathrm{T} 3 \mathrm{C}$ & $\mathrm{T} 4$ & \\
\hline \multirow[t]{8}{*}{ Histo-pathologic } & $\mathrm{T} 1 \mathrm{a}$ & 113 & 27 & 1 & 0 & 17 & 0 & 0 & 0 & 158 \\
\hline & $\mathrm{T} 1 \mathrm{~b}$ & 10 & 43 & 9 & 0 & 20 & 0 & 0 & 5 & 87 \\
\hline & $\mathrm{T} 2 \mathrm{a}$ & 0 & 2 & 11 & 1 & 6 & 0 & 0 & 0 & 20 \\
\hline & $\mathrm{T} 2 \mathrm{~b}$ & 0 & 0 & 2 & 2 & 3 & 0 & 0 & 1 & 8 \\
\hline & ТЗа & 1 & 3 & 1 & 0 & 21 & 0 & 0 & 4 & 30 \\
\hline & T3b & 0 & 0 & 0 & 0 & 0 & 1 & 0 & 3 & 4 \\
\hline & T3c & 0 & 0 & 0 & 0 & 1 & 0 & 1 & 0 & 2 \\
\hline & $\mathrm{T} 4$ & 0 & 0 & 0 & 0 & 1 & 0 & 0 & 4 & 5 \\
\hline Total & & 124 & 75 & 24 & 3 & 69 & 1 & 1 & 17 & 314 \\
\hline
\end{tabular}

Figure 3 - A) Thrombus in right renal vein (Red arrow); B) Thrombus in right renal vein (Blue arrow).

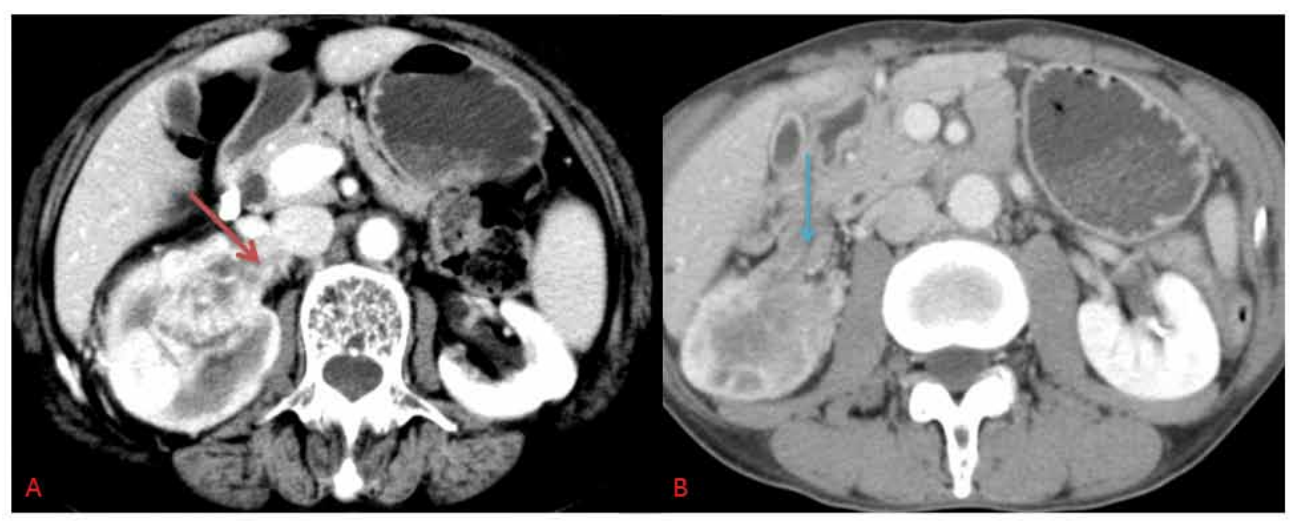

Figure 4 - A 50 year old male with renal cell carcinoma. A) Contrast enhanced axial scan thrombus in right renal vein (Blue arrow) and inferior vena cava (Red arrow). B) 3D reconstruction image. thrombus in interior in inferior vena cava (Orange arrow).

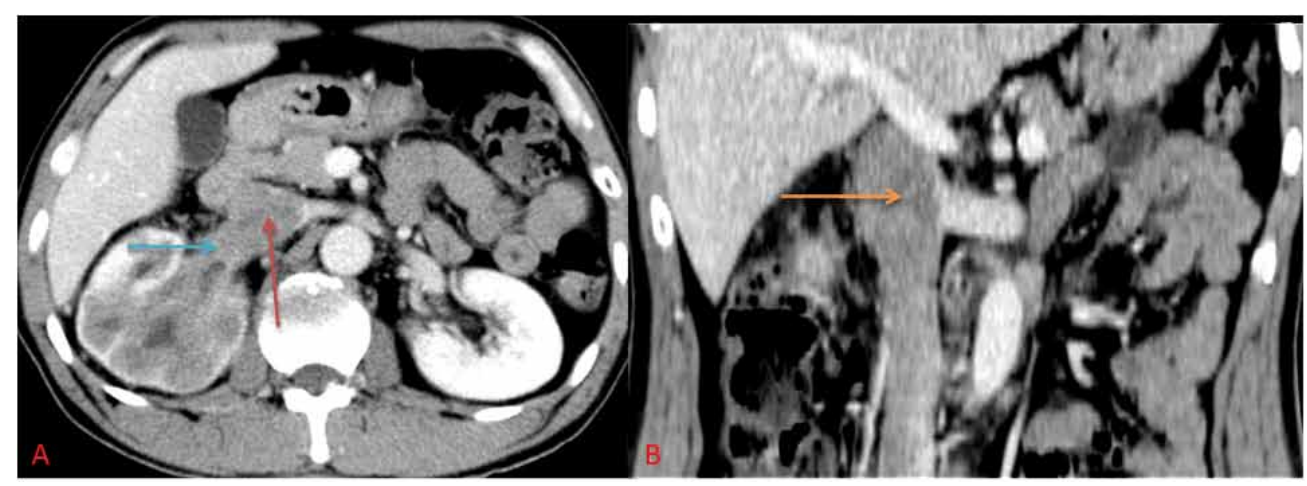


N0, 8 tumors were staged $\mathrm{N} 1$ and 9 tumors were staged N2 by MDCT(Table-3). 295 tumors (93.95\%) were correctly staged. 11 tumors (3.5\%) were overstaged and 8 tumors (2.55\%) were understaged. In the 11 tumors with false-positive lymph nodes involvement by MDCT, the nodes were larger than $1 \mathrm{~cm}$ in short-axis diameter but were characterized as reactive hyperplasia on pathology. In the 6 tumors with false negative lymph nodes, microfocuses of cancer cell metastasis were identified. Similarly, another two tumors staged N2 were understaged as $\mathrm{N} 1$ by $\mathrm{CT}$ scan because malignant cell were also found in more than one paraaortic lymph node even with a diameter less than $1 \mathrm{~cm}$. With respect to evaluation of distant metastatic disease, 8 patients were suspected in arterial phase or parachymal phase and all were confirmed by pathological examination (Table-4) (Figure-5).

\section{Statistical findings}

Agreement between MDCT and histopathologic findings was moderate for $\mathrm{T}$ stag- ing $($ Kappa $=0.469)$, fair for $N$ staging $($ Kappa $=$ 0.322 ), excellent for $M$ staging (Kappa $=0.932)$, fair for stage grouping (Kappa $=0.502) .237$ of 314 patients were correctly staged by MDCT, with an overall accuracy of $75.48 \%$. The sensitivity and specificity of MDCT in detecting perinephric fat invasion were $32.26 \%$ and $85.87 \%$, in detecting venous thrombosis were $84 \%$ and $100 \%$, in detecting adrenal gland invasion were $60 \%$ and $95.79 \%$, in detecting lymph node involvement were $50 \%$ and $96.36 \%$, in detecting distant metastasis were $100 \%$ and $99.67 \%$. In stage grouping, 237 of 314 patients were correctly staged by MDCT, with an overall accuracy of $75.48 \%$.

\section{DISCUSSION}

Since nephrectomy is still the only curative method in the treatment of RCCs, preoperative evaluation of RCCs is of great importance. MDCT now serves as the most preferable imaging modality in determining tumor location, tumor size, tumor extension, thrombosis, lymph node

Table 3 - Histopathology and multidetector computed tomography (MDCT) staging of perinephric fat invasion, adrenal invasion and tumor thrombus.

\begin{tabular}{|c|c|c|c|c|c|c|c|c|c|c|c|c|c|c|}
\hline \multirow{2}{*}{$\begin{array}{l}\text { Perinephric fat } \\
\text { invasion }\end{array}$} & & \multicolumn{2}{|c|}{ MDCT } & \multirow[t]{2}{*}{ Total } & \multirow[t]{2}{*}{ Adrenal invasion } & & \multicolumn{2}{|c|}{ MDCT } & \multirow[t]{2}{*}{ Total } & \multirow{2}{*}{$\begin{array}{l}\text { Tumor } \\
\text { thrombus }\end{array}$} & & \multicolumn{2}{|c|}{ MDCT } & \multirow[t]{2}{*}{ Total } \\
\hline & & No & Yes & & & & No & Yes & & & & No & Yes & \\
\hline \multirow[t]{3}{*}{ Histopathology } & No & 243 & 40 & 283 & \multirow{3}{*}{ Histopathology } & No & 296 & 13 & 309 & \multirow{3}{*}{ Histopathology } & No & 289 & 0 & 289 \\
\hline & & & & & & & & & & & & & & \\
\hline & Yes & 21 & 10 & 31 & & Yes & 2 & 3 & 5 & & Yes & 4 & 21 & 25 \\
\hline Total & & 264 & 50 & 314 & Total & & 298 & 16 & 314 & Total & & 293 & 21 & 314 \\
\hline
\end{tabular}

Table 4 - Histopathology and multidetector computed tomography (MDCT) staging of nodal (N) and distant metastasis (M).

\begin{tabular}{|c|c|c|c|c|c|c|c|c|c|c|}
\hline \multirow[t]{2}{*}{ Nodal metastasis } & & \multicolumn{3}{|c|}{ MDCT } & \multirow[t]{2}{*}{ Total } & \multirow[t]{2}{*}{ Distant metastasis } & & \multicolumn{2}{|c|}{ MDCT } & \multirow[t]{2}{*}{ Total } \\
\hline & & NO & N1 & N2 & & & & Mo & M1 & \\
\hline & NO & 291 & 6 & 5 & 302 & & Mo & 306 & 1 & 307 \\
\hline \multirow[t]{2}{*}{ Histopathology } & N1 & 4 & 0 & 0 & 4 & Histopathology & M1 & 0 & 7 & 7 \\
\hline & N2 & 2 & 2 & 4 & 8 & & & & & \\
\hline Total & & 297 & 8 & 9 & 314 & Total & & 306 & 8 & 314 \\
\hline
\end{tabular}


Figure 5 - A) A 57 year old female with renal cell carcinoma. The left is the kidney tumor $(A-1)$ the right is the lung metastasis (A-2). B) A 52 year old male with renal cell carcinoma. The left is the kidney tumor (B-1), the right is the metastasis in ribs (B-2).
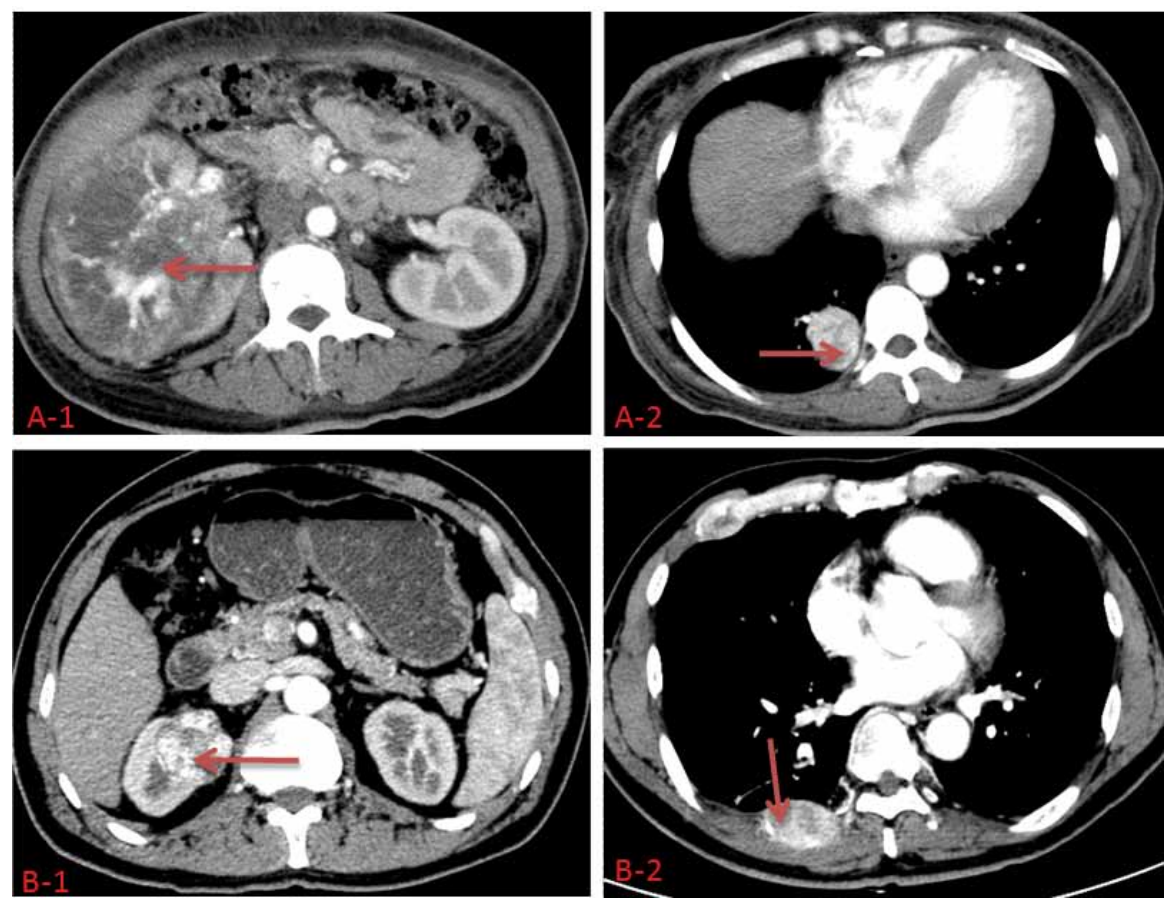

involvement and distant metastasis. Previous studies have demonstrated that the accuracy of MDCT for detection and staging of renal mass is up to $90 \%$ (7), however, it is not of limitation.

Tumor size is known as the primary component of the 2009 updated TNM classification and an important prognostic variable for RCC. NSS or partial nephrectomy is now recommended to patients with small localized tumors $(<4$ $\mathrm{cm})$ (2), and that preoperative radiographical size estimation is an essential parameter to select the appropriate treatment for RCC. Although CT measurement of the renal tumor size correlates well with the actual size of the tumor, CT scan tends to overestimate the tumor size $(8,9)$. We have found an average overestimation of 0.21 $\mathrm{cm}$ on CT scan with significant difference $(\mathrm{p}<$ 0.001). In T1a group, the overestimation was even greater, of $0.33 \mathrm{~cm}(\mathrm{p}<0.001)$. This may be the most reasonable explanation to the fact that 28 of $158(17.72 \%)$ T1a tumors were overstaged as T1b and 9 of 87 (10.34\%) T1b tumors overstaged as T2a. Similarly, Nazim found 10 of 14 (71.43\%) T1a tumors were overstaged as T1b and 14 of 44 (31.82\%) T1b tumors were overstaged as T2a (10). Kanofsky also reported that the overestimation in tumor size was enough to upstage the tumor by TNM system in 16\% of clear cell RCCs (11). Since a large portion of patients were overstaged preoperatively, these nephron sparing approaches should be considered in patients with tumor size slightly larger than $4 \mathrm{~cm}$ on CT scan without any other metastatic sign.

In prior studies, it has been shown that imaging using CT had low accuracy rates for the detection of perinephric tumor extension, as stranding in the perinephric fat is non-specific and can be due to edema, vascular engorgement or previous inflammation $(12,13)$. The presence of enhancing nodules in the perinephric fat is now considered the most reliable finding of perinephric invasion (12). Comparing with the spiral CT used before, MDCT has proved to have higher spatial resolution and better anatomy detail delineation. 
Catalano reported that MDCT had 95\% accuracy for perinephric fat infiltration with sensitivity of 96\% and specificity of 93\% (7). However, even with MDCT and three dimensional technology, Hallscheidt and Türkvatan suggested the evaluation of renal tumor extension in to perinephric fat remains a diffıcult task $(14,15)$. Türkvatan reported that 1 of $26 \mathrm{~T} 1$ tumors and 4 of $11 \mathrm{~T} 2$ tumors were overstaged as T3a. In our study, 17 of $158 \mathrm{~T} 1 \mathrm{a}$ tumors, 20 of $80 \mathrm{~T} 1 \mathrm{~b}$ tumors, 6 of 20 T2a tumors, 3 of 8 T2b tumors were overstaged as T3a. As indicated by a recent retrospective analysis of 5339 patients, 5 years cancer specific survival was $94.9 \%$ in pT1a, 92.6\% in pT1b, 85.4\% in pT2a, 70\% in pT2b and 64.7\% in pT3a (16), and patients with different staged tumors may require different treatments. Accurate stage of pT1a tumors is essential because infiltration to the perinephric fat is a contraindication to NSS. NSS is most appropriate for tumors located over the upper or lower pole or in a peripheral location and with a clear demarcation to the renal vasculature and collecting system. In our study, 158 patients with pT1a tumors; 83 were submitted to radical nephrectomy, indicating that $52.54 \%$ patients were overtreated, and $43.37 \%$ of them were due to overstaging. However, although perinephric invasion characterized by perinephric stranding and enhancing nodule in perinephric fat have not a good sensitivity and accuracy, it still should be reserved in imaging evaluation, because understaged tumors receiving more conservative therapy may lead to disastrous clinical outcome.

Approximately 23\% of RCC invade the renal veins and 7\% invade the inferior vena cava (17). Accurate definition of the presence and level of tumor thrombus preoperatively is critical for surgical planning and patient counseling. Patients with the level of tumor thrombus located inferior to the diaphragm only require laparotomy, while the detection of supradiaphragmatic extension will require a thoracoabdominal surgical approach. Although MRI has been proved superior to other modalities in tumor thrombus detecting and predicting the tumor thrombus level $(18,19)$, it is not easily available and not proper for patients with pacemaker or altered cardio-pulmonary function. In a prospective study, Halls- cheidt found no difference in tumor thrombus staging of 23 patients who underwent MRI plus MDCT preoperatively (20). More recently, Guzzo reported that accuracy rate of MDCT in predicting the superior level of tumor thrombus is 96\% (21). A low attenuation filling defect within the vein seen after injection of contrast material is the most prominent feature for venous involvement on CT scan. In our series MDCT correctly identified and localized the extent of the tumor thrombus in all patients, and the agreement between MDCT and pathological finding was excellent. However, four patients with venous wall invasion were not detected by MDCT, probably due to the local extension. Invasion of the inferior vena cava will significantly complicate surgical procedure because prosthetic reconstruction is usually required. Though negative vascular margins were achieved in all four cases, it is important to note that no imaging modality is $100 \%$ accurate and the surgeon must be prepared if more advanced disease is noted than anticipated.

Because of the low incidence of ipsilateral adrenal gland involvement (16), the current surgical trend is to spare adrenal gland during surgery. Türkvatan reported that MDCT correctly identified all six cases of adrenal involvement (15). In our study, only 3 of 13 (18.75\%) suspected adrenal involvement were confirmed by pathological findings. Because direct extension of large RCC into adrenal always compresses it into a thin tiny organ and causes local inflammation, it is difficult to distinguish it from the tumors. Our radiologist tended to be conservative and loss of tissue planes and irregular margins between the tumor and neighboring organ were all considered adrenal involvement. As indicated by Novara, patients with adrenal gland invasion had much lower 5 years cancer specific survival $(17.9 \%)$ than other subgroups (16), that conservative assessment of the adrenal gland is necessary preoperatively since an extensive resection applied in patients with abnormality suggested on CT scan may yield a better clinical outcome.

Lymph node involvement occurs in about $15 \%$ of patients in the absence of other metastasis $(22,23)$. CT has in the past been insensitive to detect nodal metastasis in normal sized nodes. 
A cutoff value in node size of $1 \mathrm{~cm}$ has been reported with a false negative rate of $10 \%$ due to reactive hyperplasia (12). Even with spiral CT, the false positive rates up to $43 \%$ have been reported (24). However, in a study by Catalano, using MDCT, 13 of 14 true positive cases for nodal metastasis were identified, reducing the false positive rate due to reactive hyperplasia to $6.3 \%$ (7). In our study, 33.33\% of patients with lymph node involvement were correctly staged, with a false positive rate of $64.7 \%$. The agreement between MDCT and pathological findings were fair (Kap$\mathrm{pa}=0.322)$, which is consistent to the findings of Türkvatan (15). This indicated that the MDCT is not a reliable modality in nodal involvement detection, and $1 \mathrm{~cm}$ size as the cutoff value is not proper. Currently, regional lymph node dissection is considered of no clinical benefit to patients with clinically negative lymph nodes (25); however, in patients with positive lymph nodes suggested preoperatively or those with progressive disease, lymph node dissection is associated with improved survival $(26,27)$.

Organ metastasis of RCC is most frequently found in the lung, bone, brain and liver (28). Likely, the metastatic lesions tend to be hypervascular. The detection of visceral metastasis is of great importance because patients with metastatic disease still benefit from radical nephrectomy combined with systemic immunotherapy $(29,30)$. In our study, all seven but one metastatic diseases were correctly detected by MDCT. Other study has proved excellent performance of this technique in metastatic lesions detection as well (15). However, lesion from an 83-year-old male incorrectly staged by MDCT was finally proved an adenoma from the gastrointestinal system, suggesting that in high risk population, multiple tumors from different tissues may occur. Therefore, a thorough preoperative search of tumors with different imaging modalities may be necessary.

\section{CONCLUSIONS}

In conclusion, MDCT scan can delineate RCCs with high accuracy, including tumor size, the presence and level of tumor thrombus and distant metastasis. However, a great proportion of tumors were overstaged by MDCT because of overestimation of tumor size and poor visualization of infiltration of the perinephric fat. In addition, as micrometastasis can not be identified and nodes with diameter $>1 \mathrm{~cm}$ may be caused by reactive hyperplasia, nodal metastatic lesion evaluation remains a difficult task.

\section{CONFLICT OF INTEREST}

None declared.

\section{REFERENCES}

1. Jemal A, Siegel R, Xu J, Ward E: Cancer statistics, 2010. CA Cancer J Clin. 2010; 60: 277-300. Erratum in: CA Cancer J Clin. 2011; 61: 133-4.

2. Jayson M, Sanders $H$ : Increased incidence of serendipitously discovered renal cell carcinoma. Urology. 1998; 51: 203-5.

3. Yaycioglu 0, Roberts WW, Chan T, Epstein JI, Marshall FF, Kavoussi LR: Prognostic assessment of nonmetastatic renal cell carcinoma: a clinically based model. Urology. 2001; 58: 141-5.

4. Israel GM, Bosniak MA: Renal imaging for diagnosis and staging of renal cell carcinoma. Urol Clin North Am. 2003; 30: 499-514.

5. Blum A, Walter F, Ludig T, Zhu X, Roland J: Multislice CT: principles and new CT-scan applications. J Radiol. 2000; 81: 1597-614.

6. Ng CS, Wood CG, Silverman PM, Tannir NM, Tamboli P, Sandler CM: Renal cell carcinoma: diagnosis, staging, and surveillance. AJR Am J Roentgenol. 2008;191: 1220-32.

7. Catalano C, Fraioli F, Laghi A, Napoli A, Pediconi F, Danti M, et al.: High-resolution multidetector CT in the preoperative evaluation of patients with renal cell carcinoma. AJR Am J Roentgenol. 2003; 180: 1271-7.

8. Mistry R, Manikandan R, Williams P, Philip J, Littler P, Foster $\mathrm{CS}$, et al.: Implications of computer tomography measurement in the management of renal tumours. BMC Urol. 2008; 8: 13.

9. Irani J, Humbert M, Lecocq B, Pires C, Lefèbvre O, Doré B: Renal tumor size: comparison between computed tomography and surgical measurements. Eur Urol. 2001; 39: 300-3.

10. Nazim SM, Ather MH, Hafeez K, Salam B: Accuracy of multidetector CT scans in staging of renal carcinoma. Int J Surg. 2011; 9: 86-90.

11. Kanofsky JA, Phillips CK, Stifelman MD, Taneja SS: Impact of discordant radiologic and pathologic tumor size on renal cancer staging. Urology. 2006; 68: 728-31.

12. Johnson CD, Dunnick NR, Cohan RH, Illescas FF: Renal adenocarcinoma: CT staging of 100 tumors. AJR Am J Roentgenol. 1987; 148: 59-63. 
13. Zagoria RJ, Bechtold RE, Dyer RB: Staging of renal adenocarcinoma: role of various imaging procedures. AJR Am J Roentgenol. 1995; 164: 363-70.

14. Hallscheidt P, Wagener N, Gholipour F, Aghabozorgi N, Dreyhaupt J, Hohenfellner M, et al.: Multislice computed tomography in planning nephron-sparing surgery in a prospective study with 76 patients: comparison of radiological and histopathological findings in the infiltration of renal structures. $\mathrm{J}$ Comput Assist Tomogr. 2006; 30: 869-74. Erratum in: J Comput Assist Tomogr. 2007; 31: 164.

15. Türkvatan A, Akdur PO, Altinel M, Olçer T, Turhan N, Cumhur $\mathrm{T}$, et al.: Preoperative staging of renal cell carcinoma with multidetector CT. Diagn Interv Radiol. 2009; 15: 22-30.

16. Novara G, Ficarra V, Antonelli A, Artibani W, Bertini R, Carini $M$, et al.: Validation of the 2009 TNM version in a large multiinstitutional cohort of patients treated for renal cell carcinoma: are further improvements needed? Eur Urol. 2010; 58: 588-95.

17. Laissy JP, Menegazzo D, Debray MP, Toublanc M, Ravery V, Dumont $E$, et al.: Renal carcinoma: diagnosis of venous invasion with Gd-enhanced MR venography. Eur Radiol. 2000; 10: 1138-43.

18. Goldfarb DA, Novick AC, Lorig R, Bretan PN, Montie JE, Pontes JE, et al.: Magnetic resonance imaging for assessment of vena caval tumor thrombi: a comparative study with venacavography and computerized tomography scanning. Urol. 1990; 144: 1100-3; discussion 1103-4.

19. Semelka RC, Shoenut JP, Kroeker MA, MacMahon RG, Greenberg HM: Renal lesions: controlled comparison between CT and 1.5-T MR imaging with nonenhanced and gadolinium-enhanced fat-suppressed spin-echo and breathhold FLASH techniques. Radiology. 1992; 182: 425-30.

20. Hallscheidt PJ, Fink C, Haferkamp A, Bock M, Luburic A, Zuna I, et al.: Preoperative staging of renal cell carcinoma with inferior vena cava thrombus using multidetector CT and MRI: prospective study with histopathological correlation. J Comput Assist Tomogr. 2005; 29: 64-8.

21. Guzzo TJ, Pierorazio PM, Schaeffer EM, Fishman EK, Allaf ME: The accuracy of multidetector computerized tomography for evaluating tumor thrombus in patients with renal cell carcinoma. J Urol. 2009; 181: 486-90; discussion 491.

22. Studer UE, Scherz S, Scheidegger J, Kraft R, Sonntag R, Ackermann $\mathrm{D}$, et al.: Enlargement of regional lymph nodes in renal cell carcinoma is often not due to metastases. J Urol. 1990; 144(2 Pt 1): 243-5.
23. Herrlinger A, Schrott KM, Schott G, Sigel A: What are the benefits of extended dissection of the regional renal lymph nodes in the therapy of renal cell carcinoma. J Urol. 1991; 146: $1224-7$

24. Heidenreich A, Ravery V: Preoperative imaging in renal cell cancer. European Society of Oncological Urology. World J Urol. 2004; 22: 307-15

25. Pantuck AJ, Zisman A, Dorey F, Chao DH, Han KR, Said J, et al.: Renal cell carcinoma with retroperitoneal lymph nodes: role of lymph node dissection. J Urol. 2003; 169: 2076-83.

26. Blute ML, Leibovich BC, Cheville JC, Lohse CM, Zincke H: A protocol for performing extended lymph node dissection using primary tumor pathological features for patients treated with radical nephrectomy for clear cell renal cell carcinoma. J Urol. 2004; 172: 465-9.

27. Hutterer GC, Patard JJ, Perrotte P, Ionescu C, de La Taille A, Salomon L, et al.: Patients with renal cell carcinoma nodal metastases can be accurately identified: external validation of a new nomogram. Int J Cancer. 2007; 121: 2556-61.

28. Rohde V. Nierenzellkarinom. In: Schmelz HU, Sparwasser C, Weidner W (eds) Facharztwissen Urologie. Springer Medizin Verlag, Heidelberg, 2006; pp. 146-58.

29. Flanigan RC, Salmon SE, Blumenstein BA, Bearman SI, Roy $V$, McGrath PC, et al.: Nephrectomy followed by interferon alfa-2b compared with interferon alfa-2b alone for metastatic renal-cell cancer. N Engl J Med. 2001; 345: 1655-9.

30. Mickisch GH, Garin A, van Poppel H, de Prijck L, Sylvester $\mathrm{R}$ : Radical nephrectomy plus interferon-alfa-based immunotherapy compared with interferon alfa alone in metastatic renal-cell carcinoma: a randomised trial. European Organisation for Research and Treatment of Cancer (EORTC) Genitourinary Group. Lancet. 2001; 358: 966-70.

\section{Correspondence address:}

Dr. Yuan Li

Department of Pediatric Surgery, West China Hospital, Sichuan University, Guoxue Xiang \#37, Chengdu, Sichuan, 610041, P.R. China Fax: +86 28 8542-2451

E-mail: str332441983@hotmail.com 